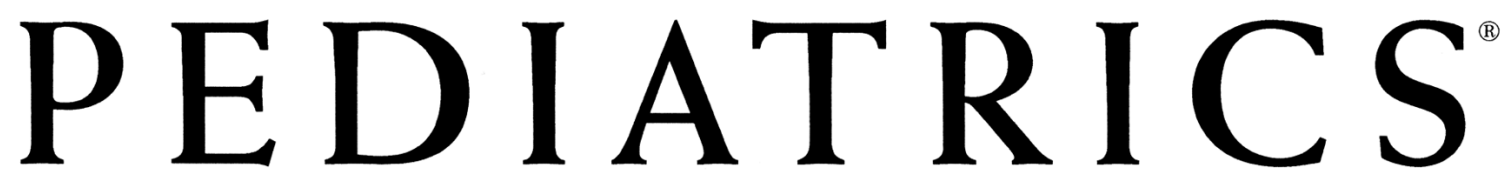

OFFICIAL JOURNAL OF THE AMERICAN ACADEMY OF PEDIATRICS

\title{
Psychosocial Implications of Disaster or Terrorism on Children: A Guide for the Pediatrician
}

Joseph F. Hagan, Jr, and the Committee on Psychosocial Aspects of Child and Family Health and and the Task Force on Terrorism

Pediatrics 2005;116;787-795

DOI: $10.1542 /$ peds.2005-1498

The online version of this article, along with updated information and services, is located on the World Wide Web at:

http://www.pediatrics.org/cgi/content/full/116/3/787

PEDIATRICS is the official journal of the American Academy of Pediatrics. A monthly publication, it has been published continuously since 1948. PEDIATRICS is owned, published, and trademarked by the American Academy of Pediatrics, 141 Northwest Point Boulevard, Elk Grove Village, Illinois, 60007. Copyright ( 2005 by the American Academy of Pediatrics. All rights reserved. Print ISSN: 0031-4005. Online ISSN: 1098-4275.

\section{American Academy of Pediatrics}




\author{
Clinical Report \\ Guidance for the Clinician in Rendering Pediatric Care
}

\begin{abstract}
Joseph F. Hagan, Jr, MD, and the Committee on Psychosocial Aspects of Child and Family Health, and the Task Force on Terrorism

\section{Psychosocial Implications of Disaster or Terrorism on Children: A Guide for the Pediatrician}

\begin{abstract}
During and after disasters, pediatricians can assist parents and community leaders not only by accommodating the unique needs of children but also by being cognizant of the psychological responses of children to reduce the possibility of long-term psychological morbidity. The effects of disaster on children are mediated by many factors including personal experience, parental reaction, developmental competency, gender, and the stage of disaster response. Pediatricians can be effective advocates for the child and family and at the community level and can affect national policy in support of families. In this report, specific children's responses are delineated, risk factors for adverse reactions are discussed, and advice is given for pediatricians to ameliorate the effects of disaster on children. Pediatrics 2005; 116:787-795; terrorism, disaster preparedness, posttraumatic stress disorder, anxiety.
\end{abstract}

$\overline{\text { ABBREVIATIONS. AAP, American Academy of Pediatrics; PTSD, }}$ posttraumatic stress disorder.

\section{INTRODUCTION}

$\mathrm{I}$ n 1999, the Committee on Psychosocial Aspects of Child and Family Health of the American Academy of Pediatrics (AAP) provided guidelines for the role of the pediatrician in responding to the psychosocial implications of disasters on children. ${ }^{1}$ Those guidelines delineated a plan for disaster preparedness and response to disaster and outlined the unique responsibility of the pediatrician at these junctures. Although that statement primarily considered natural disasters, it provided a sufficient theoretic outline for the American pediatrician's response to the terrorist attacks of September 11, 2001 in New York City, New York, and Washington, DC. The events of September 11th underscored the need for a more comprehensive resource for addressing the specific psychosocial effects of disaster on children. What has been learned of the effects on children from a tragedy of this magnitude has done much to augment our understanding of children's reactions to disaster and thus can shape planning for our re-

The guidance in this report does not indicate an exclusive course of treatment or serve as a standard of medical care. Variations, taking into account individual circumstances, may be appropriate.

doi:10.1542/peds.2005-1498

PEDIATRICS (ISSN 0031 4005). Copyright (C) 2005 by the American Academy of Pediatrics. sponse to future catastrophes to alleviate the psychosocial burden on children. Pediatricians can assist parents and community leaders not only in accommodating the unique needs of children during disasters but also by being cognizant of the psychological responses of children to reduce the possibility of long-term psychological morbidity and to help our children feel safe in their daily lives.

\section{Disasters Defined}

A disaster is a calamitous event that generally involves injury or loss of life and destruction of property; disasters can affect both small and large populations. ${ }^{2}$ These events are traumatic and customarily outside the scope of normal human experience; thus, they are likely to involve psychological as well as physical injury., ${ }^{2,3}$ For example, studies suggest that $\sim 25 \%$ of adults experience symptoms of posttraumatic stress disorder (PTSD) after acute traumatic events (see Figs 1 and 2 for symptomatology in children). ${ }^{4,5}$ The inherent resilience of children in conjunction with their specific psychological sensitivities leads to extremely variable rates of PTSD in children after acute trauma. However, the psychological effects of disaster on children are neither uniform nor universal in nature. It is widely accepted that the psychosocial manifestations in children after disaster are influenced greatly by the nature of disaster itself, the level of exposure to the disaster, the extent to which the children and those around them are personally affected by the disaster, and the individual characteristics of children, including their age and stage of development. ${ }^{2,6-8}$ In addition, children are uniquely affected by disasters because they are afflicted not only by the trauma of the event but also by their parents' fear and distress. ${ }^{7}$ Taken together, these considerations represent challenges to pediatricians and parents alike in recognizing and providing for the unique psychological needs of children.

\section{Nature of Disasters}

It is well recognized that the nature and extent of disaster can influence the psychological response of children. Acute events that produce relatively few disruptions in a child's social or living situation are generally less psychologically damaging than chronic traumatic events or events that lead to last- 
309.81 Posttraumatic Stress Disorder (PTSD)

PTSD occurs following exposure to an event that involved actual or threatened death or serious injury, or a threat to the physical integrity of self or others. The child or adolescent has symptoms in each of the following three areas for more than 1 month, causing significant distress or impairment of functioning: (1) persistent reexperiencing of the trauma, (2) avoidance of stimuli associated with the trauma and diminished general responsiveness, and (3) increased arousal or hypervigilance. In infancy, a numbing of responsiveness may also occur.
\end{abstract}

(see DSM-IV Criteria Appendix, $\mathrm{p} 339$ )

\subsection{Acute Stress Disorder}

(see DSM-IV Criteria Appendix, p 311)

\section{Infancy}

Rarely diagnosed but may take the form of extra fears or aggressive behaviors in response to stress.

\section{Early Childhood, Middle Childhood, Adolescence}

In children, distressing dreams of the event may, within several weeks, change into generalized nightmares of monsters, of rescuing others, or of threats to self or others. Reliving of the trauma may occur through repetitive play. Children may also exhibit various physical symptoms, such as stomachaches and headaches.

\section{SPECIAL INFORMATION}

PTSD follows exposure to acute or chronic stressors that involve actual or threatened death or serious injury to the child or others. The child must have reacted with intense fear, disorganized or agitated behavior, or helplessness. Stressors may be acute or chronic, single or multiple.

PTSD may be chronic and associated with significant morbidity. Symptoms of repetitive trauma re-enacting play and a sense of a foreshortened future may persist after distress is no longer present.

PTSD must be distinguished from normal bereavement. Bereavement is characterized by sadness and recurrent thoughts, but not by persistent impairment of functioning (see Sadness and Related Symptoms cluster, p 153).

Consider sexual abuse/rape ( $p$ 45). Because it may be difficult for children to report diminished interest in significant activities and constriction of affect, these symptoms should be carefully evaluated with reports from parents and teachers. In children, the sense of a foreshortened future may be evidenced by the belief that life will be too short to include becoming an adult.

Fig 1. Diagnostic and Statistical Manual for Primary Care (DSM-PC) description of PTSD. (Reproduced with permission from American Academy of Pediatrics. Child manifestations section: emotions and moods. In: Wolraich ML, Felice ME, Drotar D, eds. The Classification of Child and Adolescent Mental Diagnoses in Primary Care: Diagnostic and Statistical Manual for Primary Care (DSM-PC) Child and Adolescent Version. Elk Grove Village, IL: American Academy of Pediatrics; 1996:151.)

ing changes in the social environment. ${ }^{6,9-12}$ It is not surprising that children react differently to natural disasters than they do to human-caused disasters. ${ }^{2,5}$ Natural disasters such as storms and earthquakes are reported to have a less injurious psychological effect ${ }^{8}$ on children than human-caused disasters in which harm is inflicted intentionally, such as war and terrorism, which are associated with higher levels of distress. ${ }^{2}$ With inflicted disaster, greater psychopathology may result from children's witnessing intentional acts of violence, which are particularly incomprehensible for adults as well as children. Such disasters that defy the boundaries of human decency and rationale may engender additional horror. War entails chronic exposure to human-made violence, injury, destruction, and death. Children's responses to war are beyond the scope of this review and will not be discussed.

Thousands of children were affected significantly by the events of September 11th. Some were affected directly by losing a parent or family member, being displaced from their home or school, or witnessing the attacks. ${ }^{13}$ Still hundreds of thousands more were touched indirectly by viewing the horrific images that consumed the media for weeks after the attacks or observing initial and ongoing responses of public figures and trusted adults. Certainly, a child's personal experience related to September 11th can be predictive of that child's response. ${ }^{14}$

\section{Effects of Parental Reaction}

To address the psychological effect of disaster on children adequately, it is necessary to examine the effect of disaster on parents. Among adults in Manhattan subsequent to the September 11th attacks, rates of PTSD and depression were twice that of the normal incidence. ${ }^{15}$ Symptoms of PTSD declined in two thirds of the adult population in 3 months' time. 
The purpose of this appendix is to provide details on the diagnostic categories for the DSM-IV disorders pertinent to children. The disorders are listed in alphabetical order.

\section{Diagnostic criteria for Acute Stress Disorder $\mathbf{3 0 8 . 3}$}

A. The person has been exposed to a traumatic event in which both of the following were present:

(1) the person experienced, witnessed, or was confronted with an event or events that involved actual or threatened death or serious injury, or a threat to the physical integrity of self or others

(2) the person's response involved intense fear, helplessness, or horror

B. Either while experiencing or after experiencing the distressing event, the individual has three (or more) of the following dissociative symptoms:

(1) a subjective sense of numbing, detachment, or absence of emotional responsiveness

(2) a reduction in awareness of his or her surroundings (eg, "being in a daze")

(3) derealization

(4) depersonalization

(5) dissociative amnesia (ie, inability to recall an important aspect of the trauma)

C. The traumatic event is persistently reexperienced in at least one of the following ways: recurrent images, thoughts, dreams, illusions, flashback episodes, or a sense of reliving the experience, or distress on exposure to reminders of the traumatic event.

D. Marked avoidance of stimuli that arouse recollections of the trauma (eg, thoughts, feelings, conversations, activities, places, people).

E. Marked symptoms of anxiety or increased arousal (eg, difficulty sleeping, irritability, poor concentration, hypervigilance, exaggerated startle response, motor restlessness).

F. The disturbance causes clinically significant distress or impairment in social, occupational, or other important areas of functioning, or impairs the individual's ability to pursue some necessary task, such as obtaining necessary assistance or mobilizing personal resources by telling family members about the traumatic experience.

G. The disturbance lasts for a minimum of 2 days and a maximum of 4 weeks and occurs within 4 weeks of the traumatic event.

$\mathrm{H}$. The disturbance is not due to the direct physiological effects of a substance (eg, a drug, a medication) or a general medical condition.

\section{Diagnostic criteria for Posttraumatic Stress Disorder 309.81}

A. The person has been exposed to a traumatic event in which both of the following were present:

(1) the person experienced, witnessed, or was confronted with an event or events that involved actual or threatened death or serious injury, or a threat to the physical integrity of self or others

(2) the person's response involved intense fear, helplessness, or horror. Note: In children, this may be expressed instead by disorganized or agitated behavior.

Fig 2. Relevant Criteria of the Diagnostic and Statistical Manual of Mental Disorders (DSM-IV). (Reproduced with permission from American Academy of Pediatrics. Appendix C: sections of the relevant criteria of the Diagnostic and Statistical Manual of Mental Disorders (DSM-IV). In: Wolraich ML, Felice ME, Drotar D, eds. The Classification of Child and Adolescent Mental Diagnoses in Primary Care: Diagnostic and Statistical Manual for Primary Care (DSM-PC) Child and Adolescent Version. Elk Grove Village, IL: American Academy of Pediatrics; 1996:311, 339-304).

However, during this quarter year, children were deeply dependent on the affected parents for their emotional and psychological needs. Any effect of trauma on key or trusted adults can result in magnified psychological effect on the children they care for. ${ }^{6}$ An adult's disordered mood or behavior can add to a child's fears. Distressed adults may fail to recognize a child's distress.

Studies since the September 11th attack demon- strate that parents recognize the effects of their reactions on their children. Furthermore, parents are concerned that they are not emotionally available to adequately address their children's fears or their children's concerns of fairness and justice. ${ }^{7}$ This realization may be an added stress for parents, and 1 study reports a greater prevalence of mental distress in parents compared with nonparents, particularly in parents with symptoms of PTSD. ${ }^{13}$ 
B. The traumatic event is persistently reexperienced in one (or more) of the following ways:

(1) recurrent and intrusive distressing recollections of the event, including images, thoughts, or perceptions. Note: In young children, repetitive play may occur in themes or aspects of the trauma are expressed.

(2) recurrent distressing dreams of the event. Note: In children, there may be frightening dreams without recognizable content.

(3) acting or feeling as if the traumatic event were recurring (includes a sense of reliving the experience, illusions, hallucinations, and dissociative flashback episodes, including those that occur on awakening or when intoxicated. Note: In young children, trauma-specific reenactment may occur.

(4) intense psychological distress at exposure to internal or external cues that symbolize or resemble an aspect of the traumatic event

C. Persistent avoidance of stimuli associated with the trauma and numbing of general responsiveness (not present before the trauma) as indicated by three (or more) of the following:

(1) efforts to avoid thoughts, feelings, or conversations associated with the trauma

(2) efforts to avoid activities, places, or people that arouse recollections of the trauma

(3) inability to recall an important aspect of the trauma

(4) markedly diminished interest or participation in significant activities

(5) feeling of detachment or estrangement from others

(6) restricted range of affect (eg, unable to have loving feelings)

(7) sense of a foreshortened future (eg, does not expect to have a career, marriage, children, or a normal life span)

D. Persistent symptoms of increased arousal (not present before the trauma), as indicated by two (or more) of the following:

(1) difficulty falling or staying asleep

(2) irritability or outbursts of anger

(3) difficulty concentrating

(4) hypervigilance

(5) exaggerated startle response

E. Duration of the disturbance (symptoms in criteria $B, C$, and D) is more than 1 month.

F. The disturbance causes clinically significant distress or impairment in social, occupational, or other important areas of functioning.

Specify if:

Acute: if duration of symptoms is less than 3 months

Chronic: if duration of symptoms is 3 months or more

Specify if:

With Delayed Onset: if onset of symptoms is at least 6 months after the stressor

Fig 2. Continued.

\section{Effects on Children}

The long-term psychological morbidity among children as a result of the attacks on New York and Washington is still largely unknown. Experts suggest that the current mental health system has been ineffective in identifying and coping with the unique psychosocial burden that the events of September 11th have created. ${ }^{8,16}$ Investigators report that a surprisingly large number of children in proximity to the areas of greatest devastation received some form of counseling after the attacks. In the Manhattan area, $22 \%$ of children from the community-at-large received some form of counseling after the attacks, which was a much greater rate of counseling than seen with similar tragedies such as the Oklahoma City bombing. ${ }^{13,17}$ However, most of this counseling was received in schools. In the Washington area, the total number of children's visits to behavioral health clinics at military treatment facilities did not increase; however, there was a significant increase in the percentage of visits for anxiety disorders and acute stress reactions. ${ }^{18}$ The lack of increase in visits to behavioral health clinics coupled with a high incidence of in-school counseling demonstrates that existing or informal therapeutic relationships were the primary source of support for most children after September 11 th. ${ }^{19}$ However, it is unlikely that these interventions were sufficient to offset psychological injury for children. After September 11th, children and adolescents reported being significantly more worried about how to cope with stressful things in their lives than before the attacks. It is curious that they reported talking to their pediatric primary health care professionals and parents more about 
significant concerns in their lives after September 11th, whereas parents reported talking less to their children after September 11th about these same concerns. ${ }^{20}$ It is likely that because of the differences in perception of communication between children and adults and the lack of formal psychological evaluations for most of our nation's youth, the psychological burden of many children was not adequately assessed or addressed. In addition, pediatric practitioners in the New York City tristate area reported gaps in their self-perceived knowledge and skills necessary to address the many mental health-related concerns that they encountered in patients after September 11 th. ${ }^{21}$

For children who experience a traumatic event, some degree of behavioral symptoms and adjustment reactions are expected and are well within the normal limits of psychological response. The psychological responses of children to disasters can range from transient mild stress reactions to the more severe and prolonged consequences of PTSD. ${ }^{22}$ These responses are influenced by the gender, developmental stage, inherent resilience, and social support of the child and the level of exposure of the child to the trauma. ${ }^{2}$ Exposure to traumatic and violent events results in expressions of fear, anxiety, and depression. ${ }^{23}$ In most cases, these reactions are within the realm of normal responses to a traumatic event, and as children are helped to learn to cope with this stress, their symptoms subside. ${ }^{2,7}$

\section{Stages of Children's Response to Disaster}

Parents and caregivers can expect children to respond to disaster in distinct stages. ${ }^{2,7,24}$ The first stage, immediately after the disaster, includes reactions of fright, disbelief, denial, grief, and feelings of relief if loved ones have not been harmed. ${ }^{2}$ A great deal of altruism is often displayed by children trying to help in the aftermath of such tragedies; this may help them develop resilience and also may be a marker of resilience.

The second stage occurs a few days to several weeks after the disaster and is characterized by developmental regression in many children and manifestations of emotional distress such as anxiety, fear, sadness and depressive symptoms, hostility and aggressive behavior toward others, apathy, withdrawal, sleep disturbances, somatization, pessimistic thoughts of the future, and play demonstrating themes related to the traumatic event. 2,8 Such symptoms are part of the normal recovery process for children after a traumatic disaster and can be expected to last for a few weeks. $2,7,24$ Children who experience major loss or traumatic exposures or who are demonstrating marked distress or behavioral disorganization would benefit from counseling urgently, within 1 month of the event.

Children with adverse stress reactions and behavioral symptoms for longer than 1 month's time may be at increased risk of developing PTSD or violent and delinquent behaviors later in life. ${ }^{7,23}$ In such cases, it is appropriate and necessary for children to receive counseling from a mental health specialist. ${ }^{7}$

\section{Developmental Effects on Response to Trauma}

Children of different developmental stages interpret the world differently and at their own distinctive pace. ${ }^{7}$ Their developmental stage uniquely influences their response to traumatic events, and consequently, they display a great deal of variability in adjustment subsequent to traumatic events. Interventions to alleviate the psychological burden should be developmentally appropriate. ${ }^{25}$

The response of younger children to disaster is dominated by mood, anxiety, and behavioral symptoms. ${ }^{6}$ They are largely unable to understand the intentions and logic of others and, consequently, have great difficulty distinguishing a deliberate action from an unintentional incident. As a result, in the face of disaster, young children are more concerned with the consequences, and older children are more aware of the underlying principles of a traumatic event. ${ }^{7}$ Although older children also experience depression, their anxiety may take on specific and perhaps unrealistic forms and fears, and their behavioral reactions may be complicated by anger or despair as well as their past experiences. Older children are more sophisticated cognitively and, thus, can begin to comprehend the intent and reasoning of others and the implications of the event.

Traumatic and disrupting events can have adverse effects even on children who are too young to verbalize their distress. Although infants and toddlers may have no cognitive comprehension of a disaster, the destruction of routine and loss of loved ones can lead to regression and detachment. ${ }^{2}$ In the first year of life, such experiences can manifest as increased crying and irritability, separation anxiety, and an exaggerated startle response. ${ }^{22}$ Toddlers and preschool-aged children are likely to experience sleep terrors and nightmares and exhibit behavioral and skill regression manifesting as helplessness, clinging behavior, and increased temper tantrums. ${ }^{22}$

School-aged children often demonstrate the experience of trauma through play, expressing traumarelated themes and aggressive behavior. ${ }^{2}$ Similar to their younger counterparts, sleep disturbances and regressive behaviors such as separation anxiety are often seen. ${ }^{22}$ School-aged children also may become withdrawn or apathetic or exhibit somatization and behavioral problems. Although fear was the most common primary reaction to the events of September 11th among school-aged children, the developmental diversity of this age group leads to a wide range of responses to such trauma. ${ }^{7}$

Younger school-aged children are yet unable to comprehend another's reasoning or intent and, thus, concentrate on the direct consequences of the disaster. They tend to focus on specific details of the tragedy and on personal safety. ${ }^{7}$ They fear injury or death of family members. Conversely, older schoolaged children have a greater capacity for social cognition and empathy. They tend to display more empathy for families who were affected by the crisis, have a greater willingness to analyze how or why a tragedy occurred, and focus more on the safety of the society as a whole. ${ }^{7}$ 
The psychological response to disaster among adolescents most closely resembles that of adults; symptoms of depression and anxiety predominate. ${ }^{6}$ However, this does not lessen their risk of developing significant psychological morbidity after the experience of a severe trauma. Adolescents are a particularly vulnerable group, because they are experiencing a period of complex transitions. ${ }^{26}$ Children in this developmental stage may differ greatly in their interpretations and reactions to disasters depending on whether they have developed abstract reasoning abilities. Abstract thinking appears, on average, at 16 years of age. Most adolescents are still developing their emotional coping skills, are working to establish their independence and own identity, and are known to be especially susceptible to the development of major psychiatric disorders such as depression. ${ }^{26}$ Disasters that result in a loss of lifestyle or loved ones can result in somatization, withdrawal, apathy, and depression. ${ }^{2}$ They are likely to engage in risk-taking behaviors such as drug abuse and sexual relationships as mechanisms of coping with traumatic stress. ${ }^{26}$ Suicidal thoughts and actions are a concern. In addition, the interference with identity development in adolescence can lead to significant behavioral and emotional problems throughout their lives. Adolescents may try to mask or withhold symptoms of adjustment reactions because they think they are abnormal or inappropriate reactions. Adolescents might attempt to protect other family members who may also be upset. ${ }^{8}$ As a result, parents are at risk of underestimating the effects of disaster on their adolescents and may be in a disadvantaged position for getting their children the help that they need. ${ }^{8}$

\section{Gender, Ethnicity, and Other Influences on Response to Trauma}

Gender also has a decisive effect on the reaction of children to disaster. Boys display higher rates of behavioral symptoms and require a longer recovery period than girls. ${ }^{2,6}$ More specifically, they tend to be more antisocial and display violent and aggressive behaviors and other externalizing symptoms. When faced with disaster, girls display more internalizing symptoms such as anxiety and mood disturbances. ${ }^{2,6}$ However, they tend to be more expressive about their emotions than boys and have more frequent thoughts about the disaster.

Cultural differences may affect symptom expression. The experiences of people of Arab American, Persian American, and related ethnicities after the September 11th attacks are noteworthy. Replicating their experience during the Iran hostage crisis 25 years ago, many of these people experienced prejudice and bigotry in general, and some suffered unprovoked physical violence. Their patriotism was questioned, or it was suspected that they condoned the terrorist acts. American travelers were told by authorities to "report suspicious-looking" fellow travelers, with racial profiling as an unintended result. The description of some terrorists as "Islamic fundamentalists" has caused confusion regarding the Islamic religion and places its followers at risk for religious persecution. The teachings of Islam do not condone violent terrorist attacks.

Previous traumatic events such as personal experience of violence, abuse or neglect, foster care, or other stressors increase the risk of an adverse reaction to disaster. Previous experiences also predict more serious symptomatology, as noted in the New York City school experience. ${ }^{14}$

Tens of thousands of immigrant children and adolescents who enter the United States yearly have experienced disasters. Many immigrant families do not discuss their previous experiences with anyone outside their family, including their pediatricians. It is important that pediatricians recognize the possibility of preimmigration trauma as a potential cause of long-term psychological problems. Culturally unique responses to new traumas should be anticipated.

\section{Other Risk Factors for Adverse Reactions}

Although all children suffer to some degree from anxiety, fear, and depression when exposed to disaster, it is known that there is a subset of children who are at increased risk of developing long-term psychosocial morbidity and adverse reactions to trauma. ${ }^{6-8}$ Children with poor social support, a history of psychopathology, or a shy and fearful nature are at greater risk of trauma-associated psychopathology. ${ }^{6-8}$ Children who have experienced previous losses are also at an increased risk of adverse reactions to trauma. A disaster of any nature can awaken unresolved emotions and fears in children related to past crises. ${ }^{8}$ Parents and pediatricians should be sensitive to seemingly unrelated concerns put forth by children during times of disaster. In addition, because children are intimately dependent on adults around them for feelings of safety and well-being, children whose family members have difficulty coping with disaster are also at increased risk of adverse reactions to trauma. 2,8

Children who have had a high level exposure to or have otherwise experienced direct losses from a disaster are more susceptible to severe adverse reactions to trauma..$^{2,7,8}$ Direct witnessing of a traumatic event, victimization of the child or those close to the child, and the perception, correct or not, that one's life was in danger are known risk factors for adverse psychosocial symptoms after trauma. 8,27

Children remote from catastrophic events by both location and experience are not immune to the acute and chronic psychopathologies related to disaster. Several studies have implicated indirect television exposure to disaster as a risk factor for children's reactivity. 8,17,27-29 The amount of information that a child will find valuable in understanding a disaster largely depends on a child's developmental stage. ${ }^{8}$ Parents and caregivers should be aware that gruesome and disturbing details are likely unnecessary in facilitating a child's comprehension of a tragedy. Such information has a great potential to engender fear and may be psychologically injurious and thus impede a child's psychosocial recovery. In addition, the subjective response of a child to disaster has been demonstrated to have a high predictive value for 
symptoms of PTSD. ${ }^{27}$ Therefore, it is critical that a child's peritraumatic reaction and level of direct and indirect media exposure be monitored closely after traumatic events.

\section{Living With Fear}

This discussion has considered the responses of children and their communities to specific disaster events. Natural disasters such as earthquakes and floods and human-made disasters such as terrorist attacks and school shootings are single events. The body of literature and review described here address acute and chronic responses to individual events. Less is known about the effect of living in fear.

Is the documented recent and remarkable increase in mental health services for anxiety disorders and related conditions in children a response to the horror of September 11th or a reflection that American children no longer view their world as safe? Has our public policy of a "war on terrorism" protected, scared us, or both?

Do "terror alerts" protect or terrorize? At a minimum, such alerts should identify the seriousness of the concern and, when possible, the specifics of the risk. We should be told what our government is doing to protect us and what we might do to protect ourselves. Who benefits from alerts in which the risk is low or the anticipated events are unknown? Clearly, specific acts of defense or law enforcement may be indicated. Is there a difference between a law-enforcement alert and a public one?

The mandate to pediatricians and parents is clear. The world is perhaps a less safe place since 2001, but we are, for the most part, safe. We must allow our children to have hope. Even children living in unsafe communities or those affected by prejudice, racism, or violence depend on trusted adults to feel safe or protected so that they might anticipate a less stressladen future. We must communicate to them that they and we are almost always safe from terrorist acts or natural disasters and that we as parents, health care professionals, and community members will take care of them as we take care of one another. Although some may feel the world is a more fearful place now (an opinion that is not universal), we can help our children live with this fear, adjust to it, and plan for the future rather than remain paralyzed in fear.

\section{The Pediatrician and Disaster}

The knowledge we have gained from the events of September 11th has revealed many opportunities to improve outcomes for children who are faced with disaster. The pediatrician must be intimately involved in community disaster-preparedness plans to ensure that the unique physical and emotional needs of children are met during times of disaster. Recommendations for disaster preparedness and planning can be found online at www.aap.org/terrorism. In addition, AAP chapters have presented important local initiatives for community preparedness.

When disaster occurs, the pediatrician will be affected. Although the thrust of this statement is to guide pediatric health care professionals in their work with patients and families, it must be acknowledged that we will be affected personally as well. The pediatrician's first response might need to be to ensure personal safety and that of family and colleagues. The experience of personal injury or loss will influence one's ability to respond professionally. The toll taken on us by fear, tension, sadness, and exhaustion must be recognized and demands proactive attention. ${ }^{21}$

During times of crisis, open dialogue with school officials and community leaders is necessary to ensure that psychological care is available to children. In such scenarios, pediatricians are instrumental in creating environments in their offices, homes, schools, and communities where it is safe and acceptable for children to ask questions and attempt to understand the events around them in a supportive atmosphere. ${ }^{8}$

Pediatricians are also significant resources in assisting families in the recovery period after traumatic events. Within their offices, they are often the first to recognize children and adolescents who are experiencing adverse emotional and psychological reactions to disaster. ${ }^{8}$ It is helpful for the pediatrician to initiate this discussion; not asking a child what he or she thinks risks suggesting that the disaster is so bad that it cannot be talked about or managed. Often, when parents hear such a discussion, they are surprised at the content and nature of their child's thoughts regarding a disaster. Proper education for parents regarding what type of behaviors to expect from their children after disaster and the effect that their own reactions can have on the psychological stability of children is instrumental to the emotional well-being of our patients.

Immediate identification of the psychologically distressed child and timely referral for appropriate mental health services provides a major opportunity to improve outcomes for children exposed to disaster. The Pediatric Symptom Checklist (PSC) ${ }^{30}$ or PSC$17^{31}$ are recommended as appropriate and accessible screening tools.

\section{ADVICE FOR PEDIATRICIANS}

1. For additional study, consult the Web sites of the following organizations, which contain up-to-date information regarding children and disasters:

- The AAP disaster-preparedness Web page (www. aap.org/terrorism) includes up-to-date listings on all aspects of disaster preparedness for children, including their psychological needs. It is well linked to collateral sites, but only approved links are included.

- The National Center for Children Exposed to Violence of the Yale Child Study Center (www. nccev.org) includes disaster-specific data.

2. For advice dealing with the behavioral needs of children, consult the following sources:

- The Diagnostic and Statistical Manual for Primary Care (DSM-PC) Child and Adolescent Version 32;

- Bright Futures in Practice: Mental Health, Volumes $I$ and $\mathrm{II}^{30}$; and 
- Feelings Need Checkups Too (CD-ROM available from the AAP at www.aap.org/profed/childrencheckup.htm).

3. For community preparedness:

- Serve as a resource for families and the community in providing disaster-preparedness plans appropriate for the unique needs of pediatric patients.

- Collaborate with other professionals whose work affects children and their families, such as nurses, social workers, psychiatrists, and psychologists.

- Recognize the importance of schools in disaster preparedness. Pediatricians may wish to work with their schools or state education department to be certain that sufficient disaster plans are in place. Help community leaders recognize that there is a high likelihood that a disaster affecting a community could occur while children are in school.

- Help schools understand their roles in the aftermath of disaster. Practitioners may volunteer to serve as a resource in helping schools identify and manage children's emotional aftermath.

- Discuss evacuation and relocation planning as an essential part of community disaster preparedness. Recognizing the substantial psychosocial morbidity associated with suddenly leaving home for a strange and unknown place, insist that planners recognize the unique needs of children and families. Reunification plans for children separated from their parents must be in place. First responders should be trained to understand the needs of children who witness violence or disaster.

- Consider the resources available to families in your community. Part of psychosocial support entails helping families to identify concrete community resources that can meet their physical and emotional needs. Deficiencies in available resources detected after September 2001 can be identified and shared with community leaders.

4. For children and families:

- Be aware of patients who are at risk of adverse reactions to trauma or the development of symptoms of PTSD.

- Educate and counsel parents regarding the range of normal emotional and behavioral reactions of children to disaster and at what points they should be concerned; the effect of their own reactions to disaster on the psychological wellbeing of their children; and children who are at risk of psychological morbidity after disaster.

- Help parents recognize the potential deleterious effects of indirect disaster exposure from media and the importance of helping children understand information at the developmentally appropriate level so that children are able to correctly process and understand what they see. Help parents understand that their adult need to know for purposes of reassurance typically works as a negative in children.
- During times of crisis, stress to parents that children's media exposure should be limited and parents must be available to help children understand the relative importance of what they are seeing or hearing. For example, children may have little concept of space and need reassurance that events seen on television may in fact be quite distant from their homes.

- After disaster, screen for anxiety in all patient encounters. A simple question and expression of concern can be seen as an effective brief intervention. For many children with supportive families, peers, teachers, and others, the reaction to traumatic experience resolves in a few months. A follow-up screening 4 to 6 months after the disaster would be appropriate to identify children with continuing symptoms who may need referral for additional services.

- Be familiar with the symptoms of PTSD and be prepared to identify and refer children with the condition.

- Recognizing that some children will have experienced extreme personal loss, be prepared to address bereavement with children and families. ${ }^{33}$

Committee on Psychosocial Aspects of Child and FAMILy HeALth, 2003-2004

Jane M. Foy, MD, Chairperson

William L. Coleman, MD

Edward Goldson, MD

Cheryl L. Hausman, MD

Thomas J. Sullivan, MD

J. Lane Tanner, MD

Consultant

George J. Cohen, MD

National Consortium for Child and Adolescent

Mental Health Services

LIAISONS

F. Daniel Armstrong, PhD

Society of Pediatric Psychology

Sally E. A. Longstaffe, MD

Canadian Paediatric Society

Janet Mims, MS, CPNP

National Association of Pediatric Nurse

Practitioners

Frances J. Wren, MD

American Academy of Child and Adolescent

Psychiatry

STAFF

Karen Smith

TASK Force ON TERRORISM, 2003-2004 Joseph F. Hagan, Jr, MD, Chairperson

Marion Balsam, MD

Julia Lynch, MD

Julia McMillan, MD

Karen Olness, MD

Gary Peck, MD

Irwin Redlener, MD

David Schonfeld, MD 
Michael Shannon, MD

Richard Gorman, MD

Ex Officio Members

Carden Johnston, MD

E. Stephen Edwards, MD

Louis Z. Cooper, MD

\section{AAP STAFF}

Errol R. Alden, MD

Judy Dolins, MPH

Mike Glasstetter, JD

Jackie Noyes

Katy Grossman

\section{InVITED CONTRIBUtor Laura Cecchi}

\section{REFERENCES}

1. American Academy of Pediatrics, Committee on Psychosocial Aspects of Child and Family Health. How pediatricians can respond to the psychosocial implications of Disasters. Pediatrics. 1999;103:521-523

2. American Academy of Pediatrics, Work Group on Disasters. Psychosocial Issues for Children and Families in Disasters: A Guide for the Primary Care Physician. Washington, DC: US Department of Health and Human Services; 1995. Publication No. (SMA) 95-3022

3. Saylor CF. Introduction: children and disasters: clinical and research issues. In: Saylor CF, ed. Children and Disasters. New York, NY: Plenum Press; 1993:1-10

4. Breslau N, Davis GC, Andreski P, Peterson E. Traumatic events and posttraumatic stress disorder in an urban population of young adults. Arch Gen Psychiatry. 1991;48:216-222

5. Green BL, Lindy JD. Post-traumatic stress disorder in victims of disasters. Psychiatr Clin North Am. 1994;17:301-309

6. Pine DS, Cohen JA. Trauma in children and adolescents: risk and treatment of psychiatric sequelae. Biol Psychiatry. 2002;51:519-531

7. Beauchesne MA, Kelley BR, Patsdaughter CA, Pickard J. Attack on America: children's reactions and parents' responses. J Pediatr Health Care. 2002;16:213-221

8. Schonfeld DJ. Supporting adolescents in times of national crisis: potential roles for adolescent health care providers. J Adolesc Health. 2002;30: 302-307

9. Dohrenwend BP, Dohrenwend BS, Warheit GJ, et al. Stress in the community: a report to the President's Commission on the accident at Three Mile Island. Ann N Y Acad Sci. 1981;365:159-174

10. Laor N, Wolmer L, Mayes LC, et al. Israeli preschoolers under Scud missile attacks. A developmental perspective on risk-modifying factors. Arch Gen Psychiatry. 1996;53:416-423

11. Laor N, Wolmer L, Cohen DJ. Mothers' functioning and children's symptoms 5 years after a SCUD missile attack. Am J Psychiatry. 2001; 158:1020-1026

12. Terr LC. Childhood traumas: an outline and overview. Am J Psychiatry. 1991;148:10-20
13. Stuber J, Fairbrother G, Galea S, Pfefferbaum B, Wilson-Genderson M, Vlahov D. Determinants of counseling for children in Manhattan after the September 11 attacks. Psychiatr Serv. 2002;53:815-822

14. New York City Department of Education. Effects of the World Trade Center attack on New York City public school students. Available at: www.nycenet.edu/offices/spss/wtc_needs/coping.htm. Accessed January 24, 2005

15. Galea S, Ahern J, Resnick H, et al. Psychological sequelae of the September 11 terrorist attacks in New York City. N Engl J Med. 2002;346:982-987

16. Schonfeld DJ. Are we ready and willing to address the mental health needs of children? Implications from September 11. Pediatrics. 2004;113: 1400-1401

17. Pfefferbaum B, Nixon SJ, Tucker PM, et al. Posttraumatic stress responses in bereaved children after the Oklahoma City bombing. J Am Acad Child Adolesc Psychiatry. 1999;38:1372-1379

18. Hoge CW, Pavlin JA, Milliken CS. Psychological sequelae of September 11 [letter]. N Engl J Med. 2002;347:443

19. Galea S, Resnick H, Vlahov D. Psychological sequelae of September 11 [letter]. N Engl J Med. 2002;347:444

20. Melnyk BM, Feinstein NF, Tuttle J, et al. Mental health worries, communication, and needs in the year of the U.S. terrorist attack: National KySS survey findings. J Pediatr Health Care. 2002;16:222-234

21. Laraque D, Boscarino JA, Battista A, et al. Reactions and needs of tristatearea pediatricians after the events of September 11th: implications for children's mental health services. Pediatrics. 2004;113:1357-1366

22. Veenema TG, Schroeder-Bruce K. The aftermath of violence: children, disaster, and posttraumatic stress disorder. J Pediatr Health Care. 2002;16: 235-244

23. Monson RB. Children and terror. J Pediatr Nurs. 2002;17:62-63

24. Rollins JA. Minimizing the impact of community violence on child witnesses. Crit Care Nurs Clin North Am. 1997;9:211-220

25. Deering CG. A cognitive developmental approach to understanding how children cope with disasters. J Child Adolesc Psychiatr Nurs. 2000;13:7-16

26. Swick SD, Dechant E, Jellinek MS, Belluck J. Children of victims of September 11th: a perspective on the emotional and developmental challenges they face and how to help meet them. J Dev Behav Pediatr. 2002;23:378-384

27. Pfefferbaum B, Doughty DE, Reddy C, et al. Exposure and peritraumatic response as predictors of posttraumatic stress in children following the 1995 Oklahoma City bombing. J Urban Health. 2002;79:354-363

28. Pfefferbaum B, Nixon SJ, Tivis RD, et al. Television exposure in children after a terrorist incident. Psychiatry. 2001;64:202-211

29. Duggal HS, Berezkin G, John V. PTSD and TV viewing of World Trade Center [letter]. J Am Acad Child Adolesc Psychiatry. 2002;41:494-495

30. American Academy of Pediatrics, Maternal and Child Health Bureau. Bright Futures in Practice: Mental Health, Vol I and II. Elk Grove Village, IL: American Academy of Pediatrics; 2002

31. Gardner W, Murphy M, Childs G, et al. The PSC-17: a brief pediatric symptom checklist with psychosocial problem subscales. A report from PROS NASPN. Ambul Child Health. 1999;5:225-236

32. American Academy of Pediatrics. The Classification of Child and Adolescent Mental Diagnoses in Primary Care: The Diagnostic and Statistical Manual for Primary Care (DSM-PC) Child and Adolescent Version. Wolraich ML, ed. Elk Grove Village, IL: American Academy of Pediatrics; 1996

33. American Academy of Pediatrics, Committee on Psychosocial Aspects of Child and Family Health. The pediatrician and childhood bereavement. Pediatrics. 2000;105:445-447 


\section{Psychosocial Implications of Disaster or Terrorism on Children: A Guide for the Pediatrician}

Joseph F. Hagan, Jr, and the Committee on Psychosocial Aspects of Child and Family Health and and the Task Force on Terrorism

Pediatrics 2005;116;787-795

DOL: $10.1542 / p e d s .2005-1498$

\section{Updated Information \\ \& Services}

References

Citations

Subspecialty Collections

Permissions \& Licensing

Reprints including high-resolution figures, can be found at: http://www.pediatrics.org/cgi/content/full/116/3/787

This article cites 28 articles, 11 of which you can access for free at:

http://www.pediatrics.org/cgi/content/full/116/3/787\#BIBL

This article has been cited by 4 HighWire-hosted articles: http://www.pediatrics.org/cgi/content/full/116/3/787\#otherarticle

This article, along with others on similar topics, appears in the following collection(s):

\section{Office Practice}

http://www.pediatrics.org/cgi/collection/office_practice

Information about reproducing this article in parts (figures, tables) or in its entirety can be found online at: http://www.pediatrics.org/misc/Permissions.shtml

Information about ordering reprints can be found online: http://www.pediatrics.org/misc/reprints.shtml 